\title{
Phosphatidyl inositol-3 kinase (PIK3CA) E545K mutation confers cisplatin resistance and a migratory phenotype in cervical cancer cells
}

\author{
Wani Arjumand ${ }^{1,2,4}$, Cole D. Merry ${ }^{1,2}$, Chen Wang ${ }^{1,2}$, Elias Saba ${ }^{1,2}$, John B. McIntyre ${ }^{3}$, \\ Shujuan Fang ${ }^{1,2}$, Elizabeth Kornaga ${ }^{3}$, Prafull Ghatage ${ }^{4}$, Corinne M. Doll2,4, Susan P. \\ Lees-Miller ${ }^{1,2,4}$ \\ ${ }^{1}$ Department of Biochemistry and Molecular Biology, University of Calgary, Calgary, Alberta, Canada \\ ${ }^{2}$ Robson DNA Science Centre, Arnie Charbonneau Cancer Institute, University of Calgary, Calgary, Alberta, Canada \\ ${ }^{3}$ Translational Laboratory, Tom Baker Cancer Centre, Calgary, Alberta, Canada \\ ${ }^{4}$ Department of Oncology, University of Calgary, Calgary, Alberta, Canada \\ Correspondence to: Susan P. Lees-Miller, email: leesmill@ucalgary.ca \\ Corinne Doll, email: Corinne.Doll@albertahealthservices.ca \\ Keywords: PI3K pathway, PIK3CA-E545K, Akt, GDC-0941, cisplatin \\ Received: February 11,2016 Accepted: July 18, $2016 \quad$ Published: July 30, 2016
}

\section{ABSTRACT}

The phosphatidylinositol-3 kinase (PI3K)/Akt/mTOR signaling pathway is activated in many human cancers. Previously, we reported that patients with early stage cervical cancer whose tumours harbour PIK3CA exon 9 or 20 mutations have worse overall survival in response to treatment with radiation and cisplatin than patients with wild-type PIK3CA. The purpose of this study was to determine whether PIK3CA-E545K mutation renders cervical cancer cells more resistant to cisplatin and/or radiation, and whether PI3K inhibition reverses the phenotype. We found that CaSki cells that are heterozygous for the PIK3CA-E545K mutation are more resistant to cisplatin or cisplatin plus radiation than either HeLa or SiHa cells that express only wild-type PIK3CA. Similarly, HeLa cells engineered to stably express PIK3CA-E545K were more resistant to cisplatin or cisplatin plus radiation than cells expressing only wild-type PIK3CA or with PIK3CA depleted. Cells expressing the PIK3CA-E545K mutation also had constitutive PI3K pathway activation and increased cellular migration and each of these phenotypes was reversed by treatment with the PI3K inhibitor GDC-0941/Pictilisib. Our results suggests that cervical cancer patients whose tumours are positive for the PIK3CA-E545K mutation may benefit from PI3K inhibitor therapy in concert with standard cisplatin and radiation therapy.

\section{INTRODUCTION}

Genetic analyses of tumours have shown that aberrant phosphatidyl inositol-3 kinase (PI3K) signaling is a critical oncogenic stimulus in many different types of cancer including breast, bladder, prostate, thyroid, ovarian and non-small-cell lung cancer (NSCLC) [1-6]. Class I $\mathrm{PI} 3 \mathrm{Ks}$ are a family of lipid kinases that regulate signaling pathways involved in cell proliferation, transformation, cell survival, apoptosis and metastasis [7]. The Class I PI3K family is further divided into subclasses $1 \mathrm{~A}$ and $1 \mathrm{~B}$ where $P I K 3 C A, P I K 3 C B$ and $P I K 3 C D$ code for class $1 \mathrm{~A}$ PI3Ks and $P I K 3 C G$ codes for class $1 \mathrm{~B}$ PI3Ks [8].
The product of the $P I K 3 C A$ gene is a $110-\mathrm{kDa}$ catalytic subunit $(\mathrm{p} 110 \alpha)$ that exists in complex with a regulatory 85-kDa subunit (p85) [9]. In quiescent cells, p85 maintains the $\mathrm{p} 110 \alpha$ catalytic subunit in a low-activity state. When active, or upon growth factor stimulation, the $\mathrm{SH} 2$ domain [Rous-sarcoma (src) oncogene homology-2 domain] of the p85 subunit binds to phosphorylated tyrosine in receptor tyrosine kinases, resulting in recruitment of p110 $\alpha$ to the plasma membrane [10]. Active p110 $\alpha$ phosphorylates phosphatidylinositol 4,5-bisphosphate (PIP2) to form phosphatidylinositol 3,4,5-triphosphate (PIP3), which recruits adaptor and effector proteins containing a pleckstrin homology domain (PH domain) to 
cellular membranes including the protein kinases Akt and phosphoinositide-dependent kinase-1 (PDK-1) [11].

Akt is a well-characterized serine/threonine kinase that promotes cellular survival and is activated in response to many different growth factors, including IGF2-I, epidermal growth factor, basic fibroblast growth factor, insulin, interleukin 3, interleukin 6 , heregulin, and vascular endothelial growth factor [12]. Once at the membrane, Akt is phosphorylated at Thr308 and Ser473 by PDK1 and the mTORC2 complex, respectively [13]. Activated Akt phosphorylates and activates target proteins including GSK3 $\beta$, BAD, MDM2, caspase 9, a subset of fork-head transcription factors and mTOR, which in turn regulate phosphorylation of $\mathrm{p} 70-\mathrm{S} 6 \mathrm{~K}, 4 \mathrm{EBP} 1$ and other target proteins to regulate cell survival, proliferation, cell cycle, protein synthesis and other cellular processes $[14,15]$.

The PIK3CA gene is amplified in many cancers including head and neck, lung, gastric and cervix [16]. In addition, many human cancers including cervical cancer, express $\mathrm{p} 110 \alpha$ with activating mutations, with a reported prevalence ranging from $13-36 \%$ [17]. The majority of PIK3CA mutations cluster in "hotspots" in exon 9 (corresponding to the helical domain of PI3K p110 $\alpha$ ) and exon 20 (corresponding to the kinase domain of PI3K 110 $\alpha$ ). The most common missense mutations in PIK3CA result in replacement of glutamic acid 542 or 545 in the helical domain with lysine (E542K and E545K, respectively) or replacement of histidine 1047 in the kinase domain with arginine (H1047R) [18]. Activating mutations are associated with increased enzymatic activity independent of upstream signaling. Such constitutive activation stimulates signaling through the Akt pathway, and confers oncogenic properties such as increased cell invasion and metastasis [19]. PIK3CA mutations have also been associated with resistance to the microtubule poison paclitaxel as well as the Her2/neu antibody, trastuzumab/ Herceptin [20, 21], suggesting that activation of the PI3K pathway may contribute to treatment resistance.

Based on the critical role of the PI3K/Akt/mTOR axis in the control of cell growth, metabolism and migration, components of this pathway represent attractive candidates for targeted cancer agents. Consequently, a number of potent and selective PI3K inhibitors have recently entered early-phase clinical trials [22]. Among them is GDC-0941/Pictilisib, a potent and selective inhibitor of class I PI3K with low nanomolar potency against all four class I isoforms. GDC-0941 binds to the ATP-binding pocket of PI3K p110, preventing formation of PIP3, activation of PI3K and phosphorylation of downstream targets such as Akt [23-25]. Moreover, GDC0941 is under evaluation in phase I/II clinical trials in patients with advanced solid tumours [26] and is being evaluated in combination with cisplatin in patients with androgen receptor negative, triple negative breast cancer (https://clinicaltrials.gov/ct2/show/NCT01918306).
Previously we showed that a subset of cervical cancer patients with PIK3CA exon 9 or 20 mutations had significantly worse clinical outcomes after radiation therapy (RT) and cisplatin chemotherapy than patients whose tumours expressed wild-type PIK3CA [27]. In patients with $P I K 3 C A$ mutations, approximately $60 \%$ were E545K positive [27]. Similarly, the PIK3CA-E545K mutation was reported to be highly prevalent in a large cohort of Latin American patients with cervical tumours [28]. The aim of the present study was to evaluate the effects of PI3K p110 $\alpha$-E545K mutation on Akt pathway activation and cell survival in cervical cancer cell lines treated with radiation and/or cisplatin, and to determine the effects of PI3K pathway inhibition on the cellular response to radiation and cisplatin treatment. Our results show that cervical cancer cells expressing PIK3CAE545K are more resistant to cisplatin or cisplatin in combination with ionizing radiation (IR) than cells expressing PIK3CA-WT. Moreover, the PI3K inhibitor GDC-0941 inhibited phosphorylation of Akt and reversed the cisplatin-resistant phenotype in cervical cancer cells expressing PIK3CA-E545K. We also show that cervical cancer cells expressing PIK3CA-E545K have a more migratory phenotype than cervical cancer cells expressing PIK3CA-WT and this phenotype is also reversed by GDC0941. Taken together, these observations suggest that not only is PIK3CA a potential drug target for the treatment of patients with cervical cancer, but its inhibition may improve the delivery and efficacy of standard cisplatin chemotherapy, reduce the migratory potential of tumour cells and ultimately improve patient outcomes in patients with PIK3CA-E545K mutation who receive cisplatin as part of their treatment regimen.

\section{RESULTS}

\section{PIK3CA-E545K mutation confers resistance to cisplatin in cervical cancer cell lines}

To better understand the effects of PIK3CA-E545K mutation on cervical cancer cells, we first examined the effects of IR and cisplatin on survival of a panel of cervical cancer cell lines. For these studies, we selected HeLa (cervical adenocarcinoma derived cell line with PIK3CA-WT), SiHa (cervical squamous cell carcinoma cell line with PIK3CA-WT) and CaSki cells (a cervical squamous cell carcinoma cell line that is heterozygous for PIK3CA-E545K, Supplementary Table S1). Importantly, in all experiments cisplatin was made up and stored in PBS, consistent with a recent report that cisplatin is inactivated when reconstituted in DMSO [29]. No significant differences were observed in survival of HeLa, SiHa or CaSki cells after exposure to 1-6 Gy IR (Figure 1A), however CaSki cells were significantly more resistant to cisplatin than either HeLa or $\mathrm{SiHa}$ cells (Figure 1B). Specifically, CaSki cells showed $\sim 30 \%$ 
survival at $2 \mu \mathrm{M}$ cisplatin, compared to $\sim 3 \%$ and $\sim 1 \%$ in $\mathrm{SiHa}$ and $\mathrm{HeLa}$ respectively, suggesting that expression of PIK3CA-E545K may confer resistance to cisplatin in cervical cancer cells.

Because cancer cell lines likely bear multiple mutations that could confound interpretation of results, it was important to determine the effects of $P I K 3 C A$ E545K mutation in an otherwise isogenic background. We therefore depleted endogenous PIK3CA from HeLa cells using shRNA (to generate A5 cells) then reintroduced either shRNA-resistant $P I K 3 C A-\mathrm{WT}$ (A5-WT cells) or shRNA-resistant PIK3CA-E545K (A5-E545K cells. Supplementary Table S1 and
Supplementary Figure S1). Whole cell lysates were generated from asynchronously growing A5, A5WT and A5-E545K cells and aliquots were analyzed by western blot for the presence of the catalytic and regulatory subunits of $\mathrm{PI} 3 \mathrm{~K}$ and phosphorylation of Akt. The results confirm that A5 cells have no detectable p $110 \alpha$ expression while $\mathrm{p} 110 \alpha$ was expressed at similar levels in A5-WT and A5-E545K cells (Figure 2A and Supplementary Figure S2A). Expression of p110 $\beta$, p 85 and PTEN was also similar between the three cell lines tested indicating that loss of PIK3CA expression (A5 cells) does not affect expression of other components of the pathway (Figure 2A and Supplementary Figure S2A).

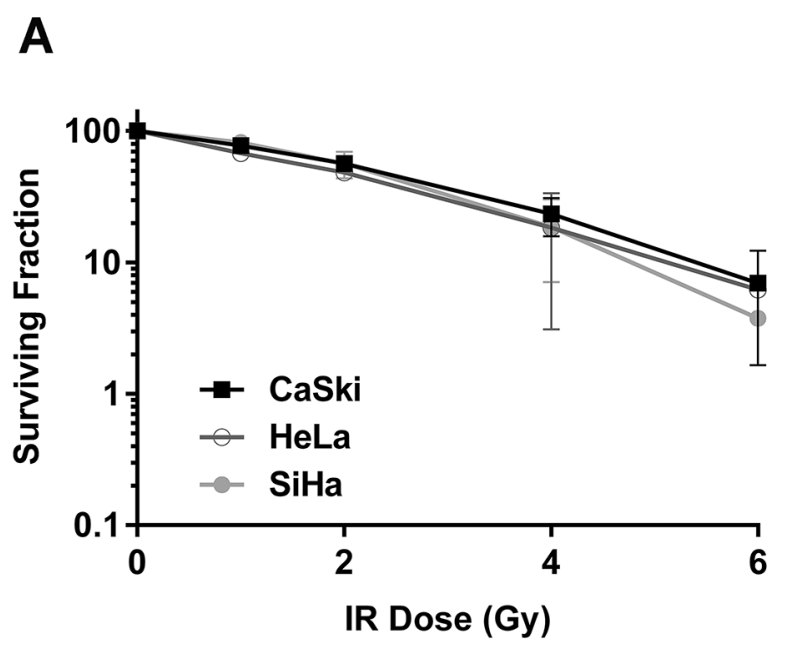

B

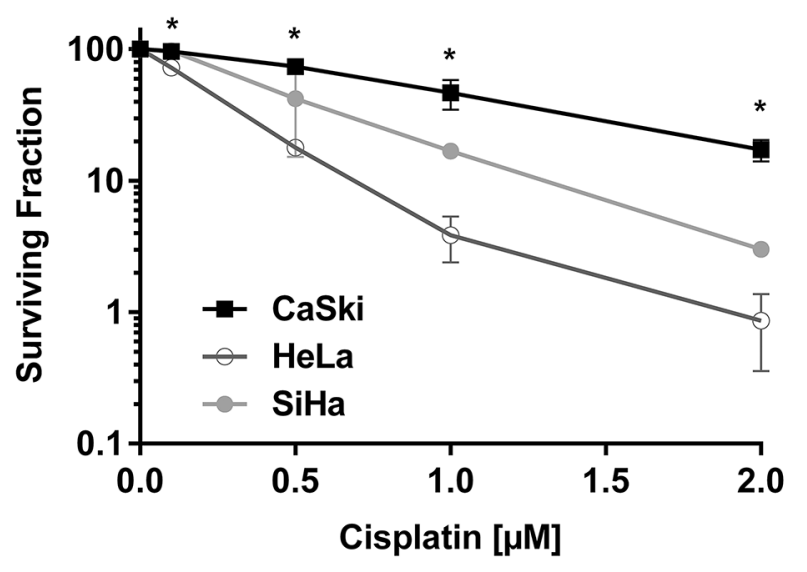

Figure 1: CaSki cells that express $P I K 3 C A-W T$ and $P I K 3 C A-E 545 K$ are resistant to cisplatin but not IR. A. Cervical cancer cell lines HeLa (PIK3CA-WT) (open circles), SiHa (PIK3CA-WT) (closed circles) and CaSki (PIK3CA-WT plus PIK3CA-E545K) (squares), were seeded on $6 \mathrm{~cm}$ plates and 24 hours later irradiated at 1, 2, 4, and $6 \mathrm{~Gy}$, respectively. Plates were incubated at $37^{\circ} \mathrm{C}$ under $5 \% \mathrm{CO}_{2}$ for 14 days prior to staining using crystal violet, and surviving colonies (clusters of $>50$ cells) were counted. Each experiment was carried out in triplicate and means of 3 separate experiments \pm S.E.M. $(n=3)$ are plotted. No statistically significant differences were observed between the three cell lines at any IR dose. B. Cells were seeded on $6 \mathrm{~cm}$ plates and 24 hours later treated with control PBS or cisplatin formulated in PBS at $0.1,0.5,1$ and $2 \mu \mathrm{M}$, respectively. Cisplatin was removed after 24 hours and replaced with fresh media. Plates were analysed after 14 days as described in Panel A. The $p$ values for the $0.1,0.5,1$ and $2 \mu \mathrm{M}$ cisplatin data points for CaSki compared to HeLa were $0.0087,0.0006,0.0227$ and 0.0071 respectively. $p$ values $<0.05$ were considered statistically significant and are indicated by asterisks. 
Total Akt protein was present in all cell lines generated, however no phosphorylation of Akt-S473 was observed in A5 cells, consistent with lack of PIK3CA expression. Myc expression confirmed expression of plasmids for PIK3CA-WT and E545K (Figure 2A).

A

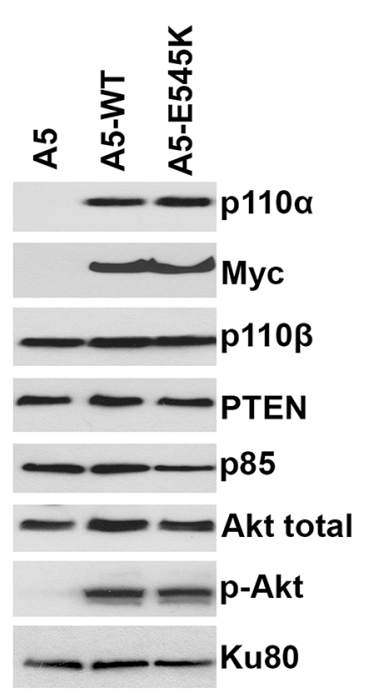

C

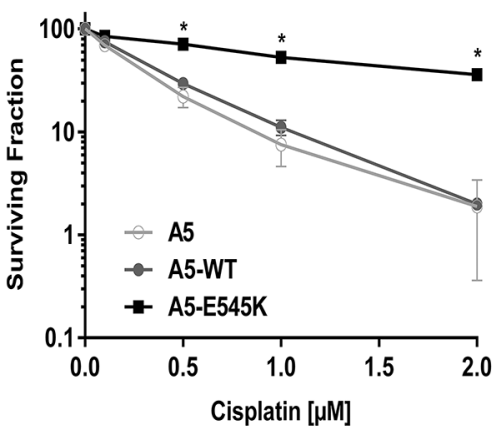

To determine whether expression of PIK3CA$\mathrm{E} 545 \mathrm{~K}$ in an isogenic background conferred resistance to IR and/or cisplatin, A5, A5-WT and A5-E545K cells were exposed to either different doses of IR (1, 2, 4 and 6 Gy) (Figure 2B) or different doses of cisplatin $(0.1,0.5,1$ and

B

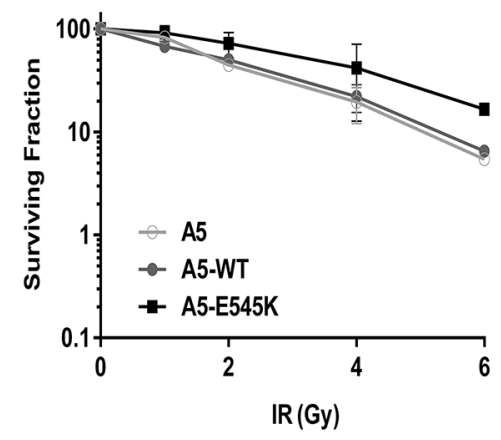

D

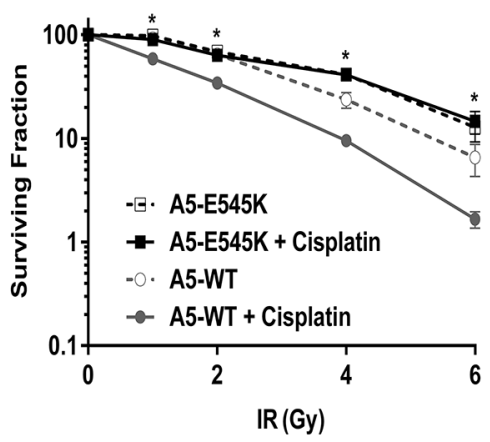

Figure 2: HeLa cells expressing $P I K 3 C A$-E545K are resistant to cisplatin A. HeLa-A5 cells (shRNA depletion of $P I K 3 C A$ ), A5 cells transfected with shRNA resistant PIK3CA-WT (A5-WT), and A5 cells transfected with shRNA-resistant PIK3CA-E545K (A5E545K) were grown under standard conditions ( $5 \%$ serum). Whole cell extracts were generated and aliquots containing $50 \mu \mathrm{g}$ protein were run on SDS PAGE. Western blots were probed with antibodies to p110 $\alpha$, p110 $\beta$, p85, Akt, Akt-pS473, PTEN, Myc (to detect stably incorporated Myc-tagged PIK3CA) and Ku80 (loading control). Quantitation of protein levels relative to the loading control (Ku80) is shown in Supplementary Figure 2A. B. A5 (shRNA depletion of PIK3CA in HeLa cells) (open circles), A5 cells transfected with shRNA resistant PIK3CA WT type (A5-WT) (closed circles), and A5 cells transfected with shRNA-resistant PIK3CA-E545K (A5-E545K) (closed squares) were either unirradiated (0), or treated with different doses of IR (1, 2, 4 and 6 Gy). Clonogenic survival assays were carried out as described in Figure 1. No statistically significant differences were observed between the three cell lines at any dose tested. C. A5, A5-WT, and A5-E545K cells as in panel B were seeded on $6 \mathrm{~cm}$ plates and 24 hours later treated with either control PBS (containing $154 \mathrm{mM} \mathrm{NaCl}$ ) or cisplatin (formulated in PBS) at $0.1,0.5,1$ or $2 \mu \mathrm{M}$, respectively. Cisplatin was removed after 24 hours and replaced with fresh media. Clonogenic survival assays were carried out as above. At $0.1,0.5,1.0$ and $2 \mu \mathrm{M}$ cisplatin, the $p$ values for A5-WT compared to A5-E545K were $0.0288,0.0004,0.0016$ and $<0.0001$, respectively. $p$ values of $<0.05$ were considered statistically significant and are indicated by the asterisks. D. A5-WT cells (open and closed circles) and A5-E545K cells (open and closed squares) were seeded on $6 \mathrm{~cm}$ plates and 24 hours later either mock treated with PBS (open symbols and dashed lines) or treated with cisplatin (formulated in PBS) at $1 \mu \mathrm{M}$ (closed symbols, solid lines). Cisplatin was removed after 24 hours and replaced with fresh media, then cells were either unirradiated (0) or irradiated at 1 , 2, 4, and 6 Gy, respectively. After 14 days, the plates were fixed, stained and colonies were counted and analyzed as above. At 1, 2, 4 and 6 Gy plus cisplatin data points, the p values for A5-WT + cisplatin compared to A5-E545K + cisplatin were $<0.0001,<0.0001,0.00045$, and 0.023 , respectively. $p$ values of $<0.05$ were considered statistically significant and are indicated by the asterisks. 
$2 \mu \mathrm{M}$, reconstituted in PBS, Figure 2C) and survival was determined using clonogenic survival assays. Our results show that A5-E545K cells are more resistant to cisplatin than either A5-WT or A5 cells (Figure 2C), whereas cellular survival after IR was similar in the three cell lines tested (Figure 2B).

Since the standard of care for cervical cancer patients is cisplatin in combination with RT, we also examined the effects of IR combined with cisplatin on cell survival. Cells were incubated with cisplatin $(1 \mu \mathrm{M}$ in PBS) or an equivalent volume of PBS for 24 hours then cisplatin was removed and replaced with fresh media. Cells were then either unirradiated (0 Gy), or irradiated with 1-6 Gy and 14 days later, survival determined using clonogenic survival assays as above. We found that A5-WT cells were sensitive to cisplatin treatment in the presence of IR, whereas A5E545K cells were resistant to cisplatin, even when cotreated with IR (Figure 2D). Together, these data strongly suggest that expression of PIK3CA-E545K in cervical cancer cells confers resistance to cisplatin and cisplatin plus IR treatment but not IR alone.

Sequencing of the $\sim 60 \%$ of patient tumour cells with PIK3CA-E545K mutation revealed that in at least $80 \%$ of the cases, the mutation was heterozygous i.e. patient tumour cells expressed both PIK3CA-WT and PIK3CA-E545K [27]. To more closely model the patient mutations, we stably expressed $P I K 3 C A$-E545K in parental HeLa cells that express endogenous $P I K 3 C A-W T$. Stable cells lines expressing both PIK3CA-WT and PIK3CA-E545K were isolated (HeLa-E545K, Figure 3A, Supplementary Figure S1C and Supplementary Figure S2B) and clonogenic survival assays were performed as above. Consistent with results in CaSki (Figure 1B) and A5-E545K cells (Figure 2C), HeLa-E545K cells were also resistant to cisplatin (Figure 3B), indicating that heterozygosity of $P I K 3 C A-E 545 \mathrm{~K}$ in an otherwise isogenic cell line is sufficient for cisplatin resistance. We next compared sensitivity to cisplatin when combined with IR in control HeLa cells ( $P I K 3 C A$-wt, Figure 4A), HeLaE545K (stable expression of PIK3CA-E545K in HeLa cells, Figure 4B) and CaSki (heterozygous for PIK3CA-E545K, Figure 4C). As seen for cervical cancer cells homozygous for the PIK3CA-E545K mutation (Figure 2D), cervical cancer cells expressing $P I K 3 C A-E 545 \mathrm{~K}$ in combination with $P I K 3 C A$-wt (HeLa-E545K and CaSki) were more resistant to cisplatin in combination with IR than HeLa cells expressing only PIK3CA-WT (Figure 4 compare black bars in panels $\mathrm{A}$ to black bars in panels $\mathrm{B}$ and $\mathrm{C}$ ), confirming that heterozygous expression of PIK3CA-E545K confers resistance to cisplatin, even in the presence of IR.

\section{Expression of $P I K 3 C A-E 545 K$ results in constitutive activation of the AKT pathway in cervical cancer cell lines}

Previous studies in NSCLC and breast cancer cells have shown that the $P I K 3 C A-\mathrm{E} 545 \mathrm{~K}$ mutation results in constitutive activation of the PI3K pathway and enhanced signaling through the Akt pathway $[30,31]$. To determine whether cervical cancer cells bearing the PIK3CA-E545K mutation also displayed enhanced PI3K signaling, A5WT, A5-E545K and HeLa-E545K cells were grown under reduced serum conditions and AKT phosphorylation was assessed by immunoblotting with a phosphospecific antibody against the mTORC2 phosphorylation site Akt-S473. Phosphorylation of RSK at S380 was also evaluated as an indication of down regulation of ERK signaling in response to serum starvation [32]. In A5 cells (HeLa expressing PIK3CA-WT) grown in $0.2 \%$ serum (serum starved conditions), phosphorylation of Akt-S473 and RSK-S380 was reduced by at least $80 \%$ compared to the same cells grown under 5\% serum (A5WT, Supplementary Figure S3, lanes 1 and 2), whereas serum-starved A5-E545K cells (Supplementary Figure S3A and S3C, lanes 3 and 4) or HeLa-E545K cells (Supplementary Figure S3B and S3D, lanes 3 and 4) showed higher levels of both Akt-S473 phosphorylation (50-60\%) and RSK-S380 phosphorylation (60-80\%) after serum starvation, consistent with constitutive activation of the PI3K/Akt pathway in these cells. Our results support previous studies [13] showing that PIK3CAE545K mutation results in constitutive activation of the Akt pathway in human cells. Since activating mutations in PIK3CA have been associated with resistance to various chemotherapeutic agents $[20,21]$, these results suggested a potential mechanism of cisplatin resistance in cervical cancer cells expressing $P I K 3 C A$-E545K and support the hypothesis that inhibiting the PI3K pathway may restore cisplatin sensitivity in cervical cancer cells expressing PIK3CA-E545K.

\section{Inhibition of the PI3K/Akt pathway with GDC- 0941 sensitizes PIK3CA-E545K expressing cells to cisplatin}

GDC-0941 is a class I selective PI3K inhibitor that has been shown to suppress PI3K and Akt signaling in breast cancer cell lines with PI3K pathway activation [33]. We therefore wanted to determine whether inhibition of PI3K/Akt signaling by GDC-0941 in cervical cancer cells expressing $P I K 3 C A-E 545 \mathrm{~K}$ restored sensitivity to cisplatin and/or cisplatin + IR. To determine the optimal dose of GDC-0941 to use in our experiments, we first incubated cells with various concentrations of GDC-0941 for 6-72 hours, harvested cells and probed for Akt-pS473 phosphorylation. Since GDC-0941 is freely soluble in DMSO but not in water or ethanol (http://www.selleckchem.com/products/GDC-0941.html), for all experiments, GDC-0941 was made up as a stock solution in DMSO and diluted in cell media to give a final concentration of $0.5,1$ or $2 \mu \mathrm{M}$ and, in each case, a final DMSO concentration of $0.01 \%$. Control reactions contained $0.01 \%$ DMSO alone. Incubation with $0.5,1$ or 
$2 \mu \mathrm{M}$ GDC-0941 reduced Akt-pS473 phosphorylation indicating it inhibits the PI3K/Akt pathway in our panel of cervical cancer cells (Supplementary Figure S4).

To determine the effect of GDC-0941 on survival in the presence of cisplatin or cisplatin plus IR, cells were incubated with cisplatin (made up in PBS) in the presence of either $0.5 \mu \mathrm{M}$ GDC-0941 (made up in DMSO to give a final concentration of $0.01 \%$ ) or an equivalent volume of DMSO (corresponding to a final concentration of $0.01 \%$ ). Importantly, cisplatin has been shown to retain

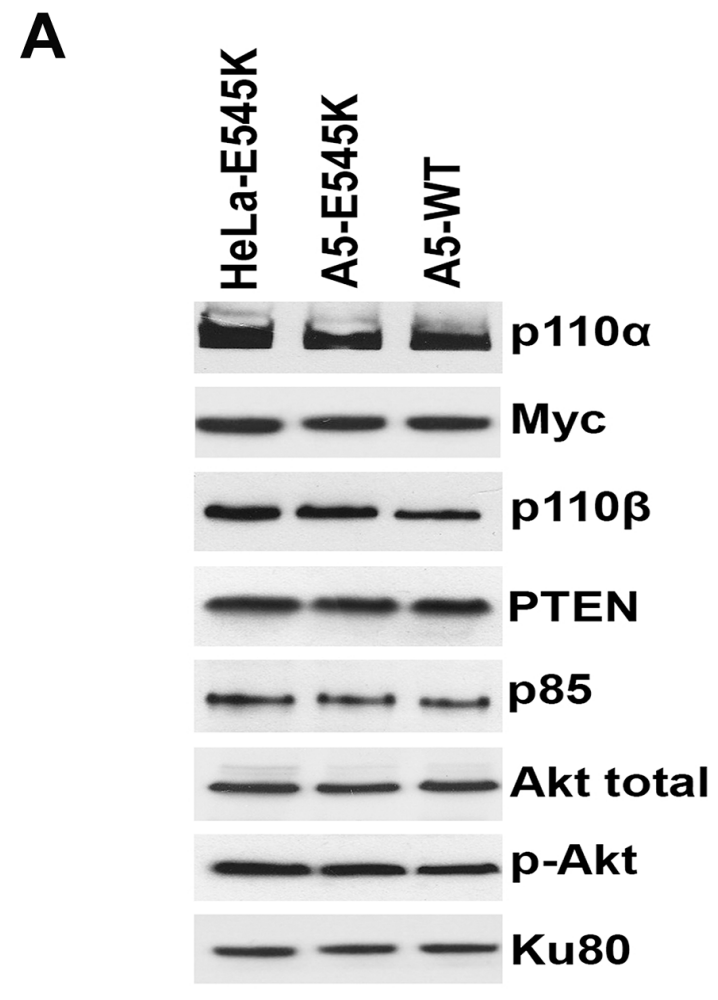

B

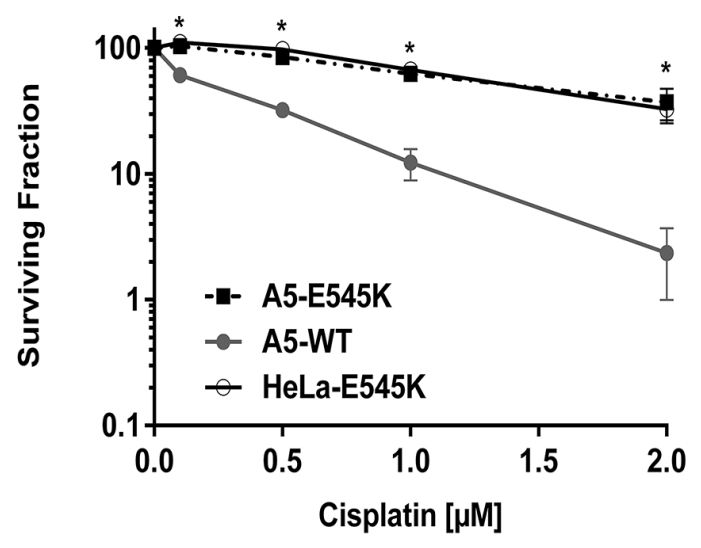

Figure 3: HeLa cells stably expressing both PIK3CA-E545K and PIK3CA-WT are resistant to cisplatin A. HeLa cells stably expressing Myc/DDK-tagged PIK3CA-E545K (HeLa-E545K) were generated as described in Materials and Methods. Aliquots containing $50 \mu \mathrm{g}$ protein were run on SDS PAGE, immunoblotted and probed with antibodies to $\mathrm{p} 110 \alpha$ and $\beta$, Myc (to detect transfected PIK3CA-E545K), p85, PTEN and Ku80 (loading control). Quantitation of protein levels relative to the loading control (Ku80) is shown in Supplementary Figure S2B. B. A5-WT (closed circles), A5-E545K (closed squares) and HeLa cells overexpressing PIK3CA-E545K (HeLa-E545K) (open circles) were seeded on $6 \mathrm{~cm}$ plates and 24 hours later treated either with PBS (154 mM NaCl) as control, or cisplatin (formulated in PBS) at $0.1,0.5,1$ or $2 \mu \mathrm{M}$. Cisplatin was removed after 24 hours and replaced with fresh media and plates were analysed by clonogenic survival assays as in Figure 2. For A5-WT and A5-E545K, at the 0.1, 0.5, 1 and $2 \mu \mathrm{M}$ cisplatin data points, the $p$ values were $0.010,0.010,0.0034$ and 0.0301 respectively. Similarly, for HeLa-E545K and A5-WT, the $p$ values for $0.1,0.5,1$ and $2 \mu \mathrm{M}$ cisplatin data points were $0.0052,0.0024,0.0038$ and 0.017 respectively. $p$ values of $<0.05$ was considered statistically significant and are indicated by the asterisks. 

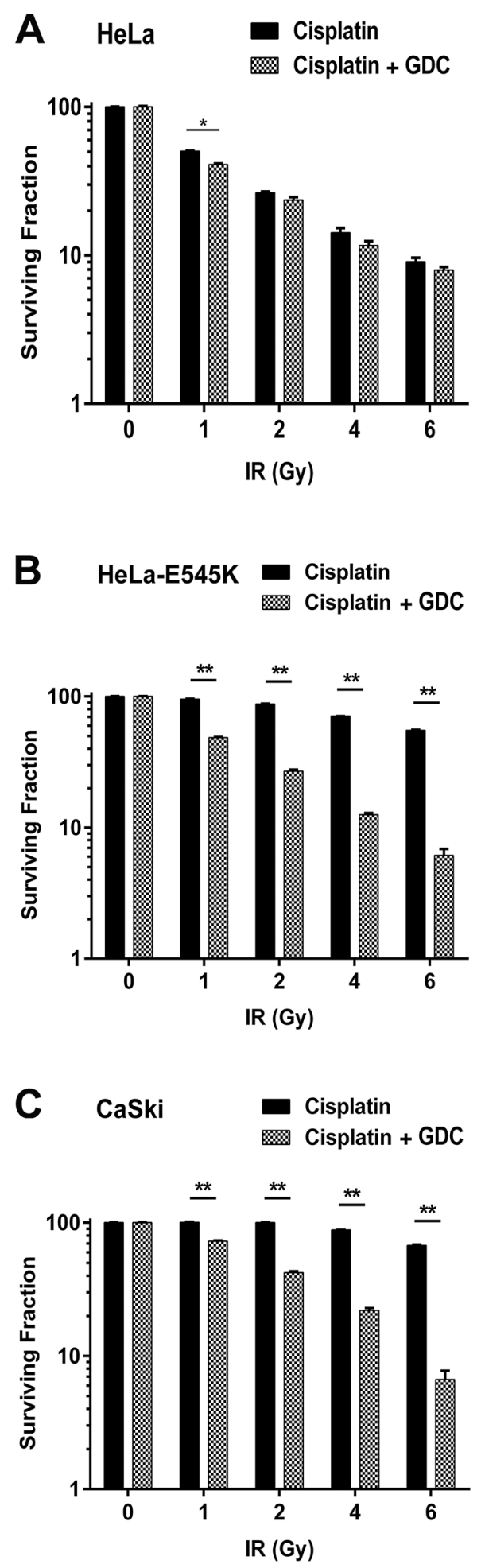

Figure 4: GDC-0941 restores cisplatin sensitivity in PIK3CA-E545K expressing cells. Cervical cancer cell lines HeLa (PIK3CA-WT, panel A. HeLa cells overexpressing PIK3CA-E545K (HeLa-E545K, panel B. and CaSki (PIK3CA-WT plus PIK3CAE545K, panel C. were seeded on $6 \mathrm{~cm}$ plates and 24 hours later treated with cisplatin (formulated in PBS) at $1 \mu \mathrm{M}$ and GDC-0941 (formulated in DMSO) at $0.5 \mu \mathrm{M}$ (final concentration $0.01 \% \mathrm{DMSO}$ ) or $0.01 \% \mathrm{DMSO}$ alone, as indicated by the dark and gray/hatched bars, respectively. After 24 hours, media was replaced with fresh media and then the cells were either unirradiated (0) or irradiated at 1,2, 4 , and $6 \mathrm{~Gy}$, as indicated. Plates were incubated at $37^{\circ} \mathrm{C}$, under $5 \% \mathrm{CO}_{2}$ for 14 days, then fixed, stained and colonies were counted as above. Statistical significance was determined using multiple t-tests between cisplatin plus IR and cisplatin plus GDC-0941 at each dose of IR. For HeLa cells, p values were $0.00037,0.082,0.12$ and 0.19 respectively. For HeLa-E545K and CaSki cells, all values were $<0.0001$ and are represented by $* *$. 
activity when incubated in media in the presence of $0.01 \%$ DMSO [29]. After 24 hours, media was removed, replaced with fresh media and cells were either unirradiated $(0$ Gy) or irradiated with 1-6 Gy and percent cell survival determined using clonogenic survival assays. As shown in Supplementary Figure S5, incubation of cells with $0.5 \mu \mathrm{M}$ GDC-0941 alone for 24 hours reduced survival by approximately $40 \%$ in both CaSki and HeLa-E545K while only reducing survival by about $10 \%$ in HeLa cells, suggesting that GDC-0941 is more toxic to cervical cancer cell lines with the PIK3CA-E545K mutation, and consequent misregulated Akt signaling, than cells with endogenous $P I K 3 C A$ signaling.

Significantly, GDC-0941 restored sensitivity in both HeLa-E545K (hatched bars, Figure 4B) and CaSki cells (hatched bars, Figure 4C) that had been treated with cisplatin plus IR, with little effect on control HeLa cells (Figure 4A). Similar results were seen in A5-WT and A5-E545K cells treated with cisplatin and GDC-0941 (Supplementary Figure S6). Together, these data show that cervical cancer cells bearing the PIK3CA-E545K mutation have activated PI3K signaling and resistance to cisplatin that can be overcome by inhibition of PI3K with GDC-0941.

\section{PIK3CA-E545K cells have an enhanced migratory phenotype, which can be suppressed by treatment with GDC-0941}

Previous studies have shown that activating mutations in PIK3CA promote invasion of human cancer cells and that cells expressing $P I K 3 C A$-E545K migrate faster in cell-based assays [14]. To determine the effects of PIK3CA-E545K mutation on cell migration in our cervical cancer cell lines, scratch assays were performed on confluent cells (as described in Materials and Methods) and cells were allowed to recover for variable lengths of time, up to 48 hours. Our results suggest that PIK3CAE545K expressing cells migrate across the scratch faster than cells expressing PIK3CA-WT (Supplementary Figure $\mathrm{S} 7$ ), and that cell migration is attenuated in the presence of GDC-0941, particularly in cells expressing PIK3CAE545K (Figure 5). Moreover, GDC-0941 reduced cell migration in cells treated with cisplatin and IR. The relative scratch width was greater in HeLa-E545K and CaSki cells than HeLa cells at all time points, consistent with GDC-0941 inhibition of both constitutively active PI3K and endogenous PI3K (Figure 6).

We concluded that the differences in migration pattern were unlikely to be due to changes in proliferation since the cell lines had similar growth curves by trypan blue staining when grown under normal conditions with 5\% serum (Supplementary Figure S8). We also considered it possible that the cells failed to migrate across the wound because of drug or IR-induced cell death. To test for this possibility, experiments were set up as for scratch assays, but percent viability was determined using trypan blue exclusion assays. As shown in Supplementary Figure S9, 48 hours post scratch, viability in Hela cells treated with cisplatin/IR and GDC-0941 was approximately 90\% compared to cells treated with cisplatin and IR without GDC. In contrast, in CaSki and HeLa-E545K, the \% viability was reduced to about $70 \%$ after GDC treatment. Thus, we cannot exclude the possibility that part of the reason for decreased migration across the scratch in GDC-0941 treated cells was in part due to cell death. Nevertheless, these experiments confirm our findings that cells expressing $P I K 3 C A$-E545K are more sensitive to GDC-0941 than those expressing PIK3CA-WT.

Finally, to confirm results from scratch assays, we performed transwell migration assays (as described in Materials and Methods). Consistent with results from scratch assays, cervical cancer cells carrying the PIK3CAE545K mutation (HeLa-E545K, Figure 7C, and CaSki, Figure 7D), displayed enhanced migration compared to cells expressing wild type PIK3CA. Moreover, as in scratch assays, treatment with GDC-0941 (in combination with radiation and cisplatin) reduced cell migration in CaSki and HeLa-E545K cells (Figure 7). Together, these results reveal that expression of PIK3CA-E545K in cervical cancer cell lines promotes both cisplatin resistance and a cell migratory phenotype and that both cisplatin resistance and cell migration can be mitigated at least in part, by inhibition of the PI3K pathway using GDC-0941.

\section{DISCUSSION}

Despite the introduction of vaccines to high-risk human papilloma viral strains, cervical cancer remains a major source of cancer death, particularly in underdeveloped countries. Indeed, it is the third most common cancer diagnosis in women worldwide, and the fourth leading cause of cancer deaths [34]. The standard-ofcare for locally advanced cervical cancer patients is radical radiation therapy (RT) in combination with cisplatin chemotherapy, yet $30-40 \%$ of patients are not cured of their disease. Cisplatin is also the most common chemotherapeutic agent used with RT in the adjuvant post-surgical setting for patients with cervical cancer. Although the addition of cisplatin chemotherapy to RT has been shown to improve survival vs RT alone, this comes at the expense of increased toxicity $[35,36]$. Moreover, the mechanisms of chemoradiotherapy resistance remain poorly understood.

We have previously shown that patients with early stage cervical cancer (IB/II) with PIK3CA exon 9 or 20 mutations treated with radical RT in combination with cisplatin had significantly worse outcome than those whose tumours expressed PIK3CA-WT [27]. The majority of these mutations (almost 60\%) were $P I K 3 C A$-E545K, and in approximately $80 \%$ of cases the mutation was 
heterozygous. A similar frequency of E545K mutation was reported recently in a large cohort of Latin American patients with cervical tumours [28]. Here we show that the CaSki cervical cancer cell line that is heterozygous for $P I K 3 C A$-E545K, is significantly more resistant to cisplatin than $\mathrm{SiHa}$ and HeLa that express PIK3CA-WT. Similarly, in HeLa cells in which the endogenous PIK3CA transcript was knocked down using shRNA and then restored with stably expressed shRNA-resistant $P I K 3 C A$ WT or shRNA-resistant PIK3CA-E545K, as well as HeLa cells expressing both $P I K 3 C A$-WT and PIK3CA-E545K, expression of $P I K 3 C A$-E545K correlated with cisplatin resistance and a more migratory phenotype, even when

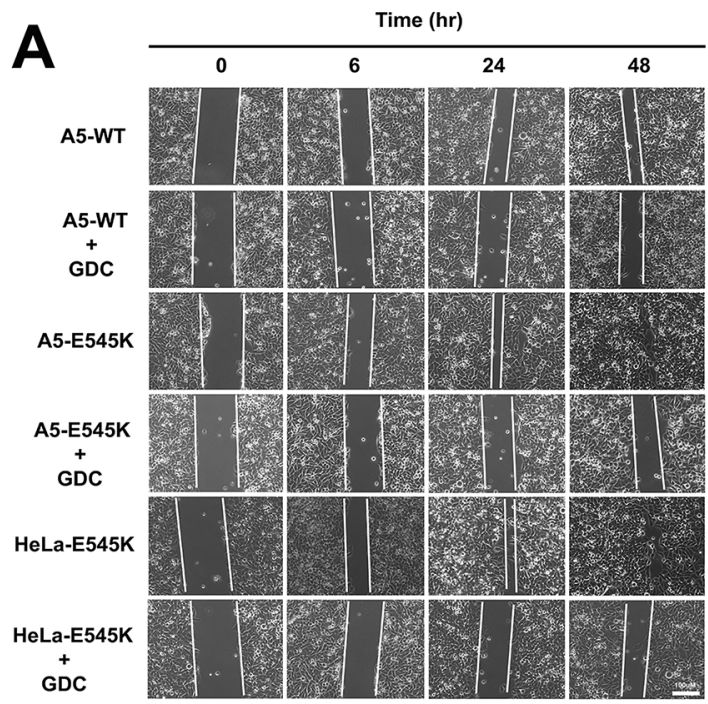

C

A5-E545K
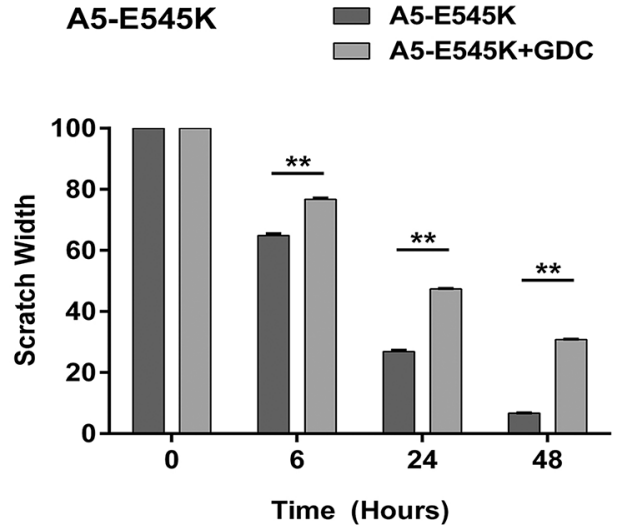

cells were co-treated with IR. Moreover, the selective class I PI3K inhibitor, GDC-0941 restored cisplatin sensitivity and slowed cellular migration in PIK3CAE545K expressing cells. PIK3CA-E545K expression appeared to have a dominant phenotype since cisplatin resistance and enhanced migration were observed in cells expressing PIK3CA-E545K plus PIK3CA-WT as well as $P I K 3 C A$-E545K alone. Reduced cellular viability and migration was also observed in PIK3CA-WT expressing cells treated with GDC-0941, suggesting that GDC0941 down-regulates signaling from endogenous PI3K signaling pathways, not only when it is over activated by E545K mutation.
B

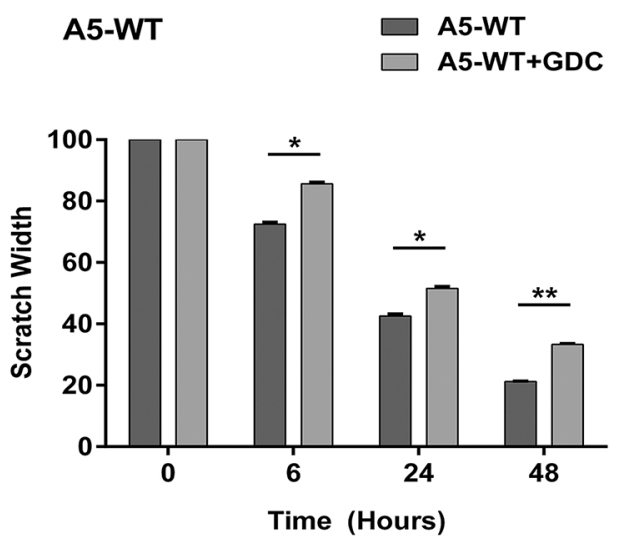

D
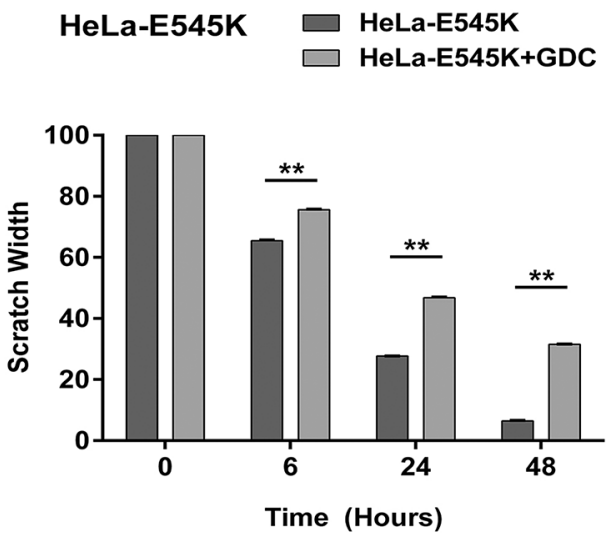

Figure 5: Stable cells expressing PIK3CA-E545K have a more migratory phenotype that is reversed by GDC-0941 A. A5-WT, A5-E545K and HeLa-E545K were grown to confluency on $6 \mathrm{~cm}$ plates and pre-treated with $1 \mu \mathrm{M}$ GDC-0941 (formulated in DMSO) or an equivalent volume of DMSO (final concentration $0.01 \%$ ) for 24 hours and the next day scratches were made and wound healing was observed as described in Materials and Methods. Representative images are shown. Scale bar $=100 \mu \mathrm{m}$. B. Average scratch widths, normalized to the width at 0 hours, from three separate experiments with standard deviation are shown using multiple comparison tests. For each cell line the reduction in the width of the scratch \pm GDC-0941 at 6, 24 and 48 hrs was compared. For A5-WT p values were $0.00011,0.00065$ and $<000.1$ respectively. P values $<0.005$ are indicated by ** and $<0.0001$ by ***. C. As in panel B but for A5-E545K cells minus and plus GDC-0951. D. As in panel B but for HeLa-E545K cells minus and plus GDC-0941 at 6, 24 and 48 hrs. 


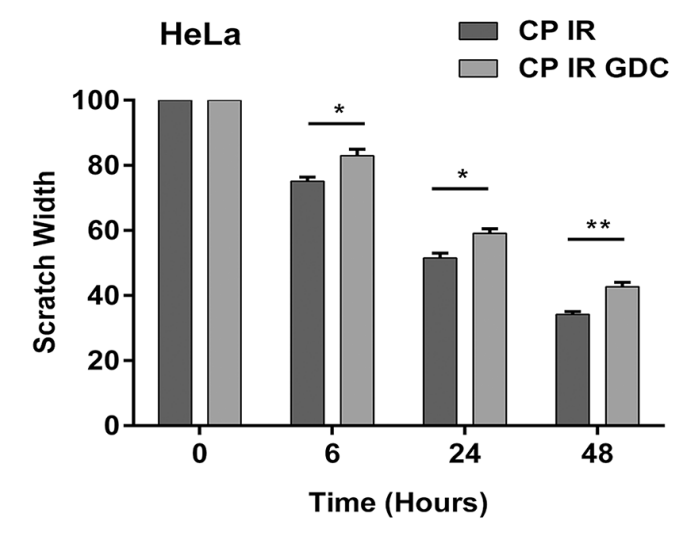

B
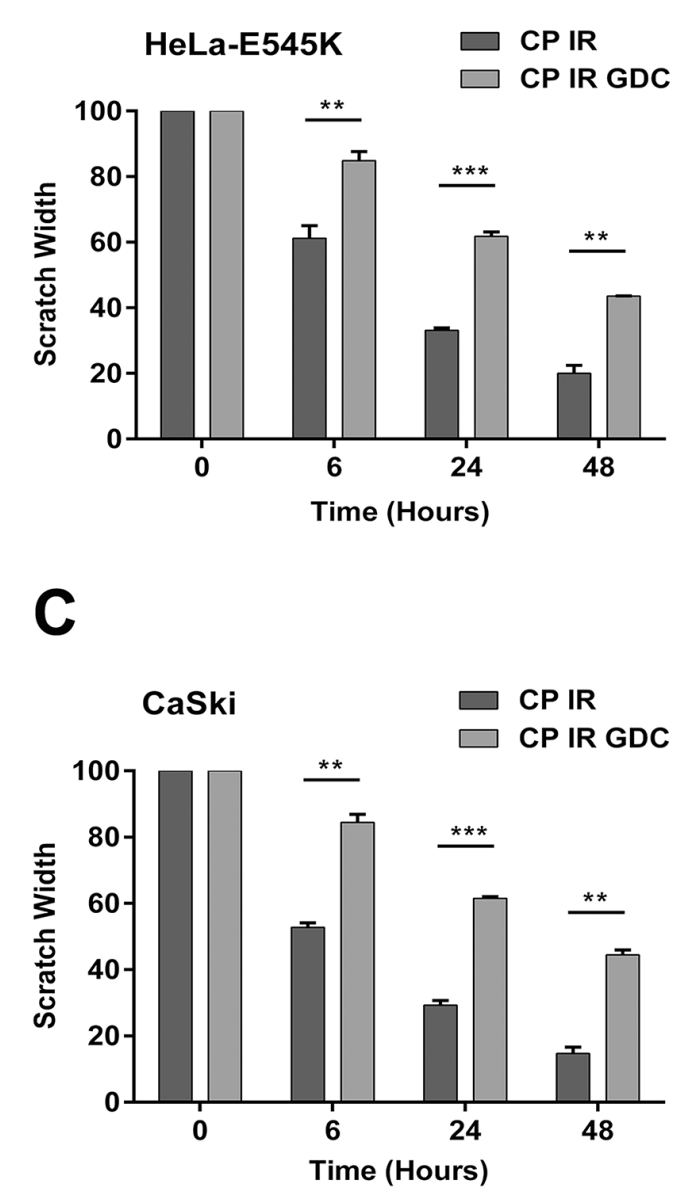

Figure 6: Cervical cancer cells expressing PIK3CA-E545K have a more migratory phenotype in scratch assays after cisplatin/IR treatment that is reversed by GDC-0941. Scratch assays were carried out as in Figure 5, but cells were either untreated or pre-treated with $1 \mu \mathrm{M}$ GDC-0941 (formulated in DMSO) or an equivalent volume of DMSO (final concentration $0.01 \%$ ), radiation (2Gy) and cisplatin (formulated in PBS) at $1 \mu \mathrm{M}$ for 24 hours. Scratches were made and wound healing was observed $0,6,24$, and 48 hours after initiation of the scratch. For HeLa cells panel A. treated with cisplatin plus IR compared to cisplatin plus IR plus GDC-0941 at 6, 24, and 48 hours, the $\mathrm{p}$ values were $0.031,0.02,0.0057$, respectively. For HeLa-E545K cells panel B. treated with cisplatin plus IR compared to cisplatin plus IR plus GDC-0941 at 6, 24, and 48 hours, the p values were $0.0076,<0.0001$, and 0.00068 , respectively. C. For CaSki cells panel C. treated with cisplatin plus IR compared to cisplatin plus IR plus GDC-0941, at 6, 24, and 48 hours, the p values were 0.00032 , $<0.0001$, and 0.00027 , respectively. 
Taken together, our studies suggest that constitutive activation of PI3K through E545K mutation leads to activation of Akt, likely through the mTORC2 pathway, as evidenced by enhanced phosphorylation of Akt-pS473 [15]. Activation of the PI3K pathway has been linked to the resistance of multiple chemotherapeutic drugs. The mechanism is poorly understood, but has been proposed to involve Akt-dependent activation of pro-survival pathways [37]. Cisplatin is a widely used chemotherapeutic agent that acts as a crosslinking agent, producing bulky adducts that can be repaired by nucleotide excision repair [38],
Fanconi anemia and homologous recombination DNA repair pathways [39]. Mechanisms of resistance frequently involve altered DNA repair pathways or mechanisms of cisplatin uptake/excretion as well as up regulation of cellular pathways to inactivate cisplatin [38]. Precisely how these pathways might be affected by PI3K activation in cervical cancer cells will be an important area for further investigation.

Cell migration is a complex and highly coordinated process that is important for diverse biological processes, including embryonic morphogenesis, immune
A

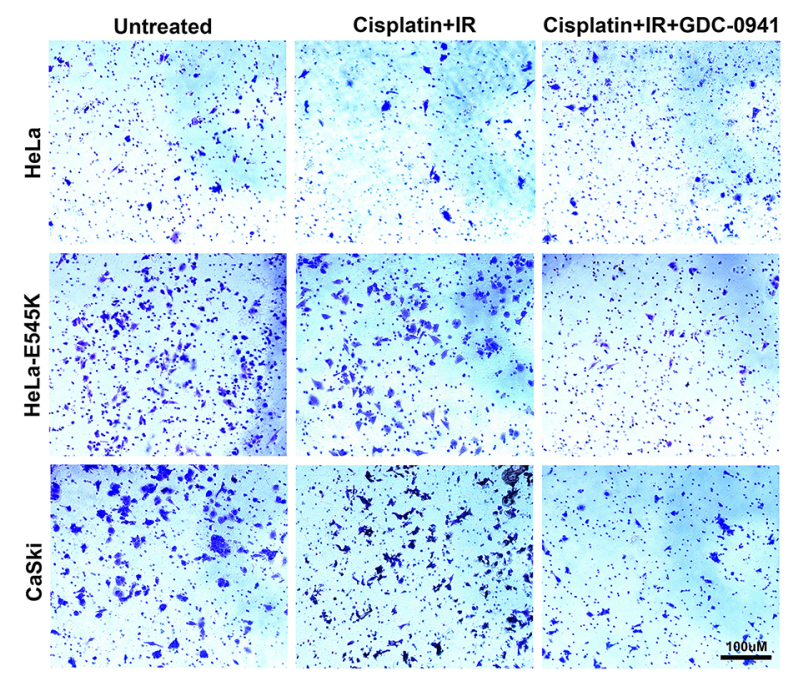

C

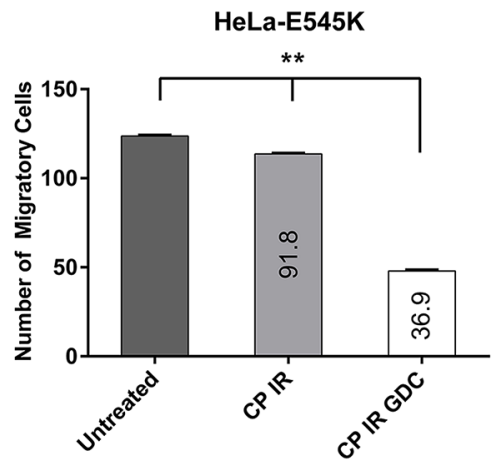

B

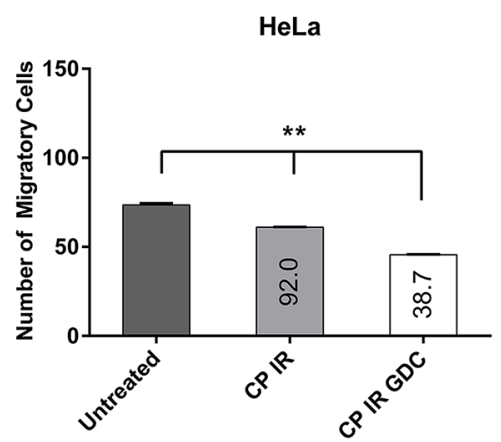

D

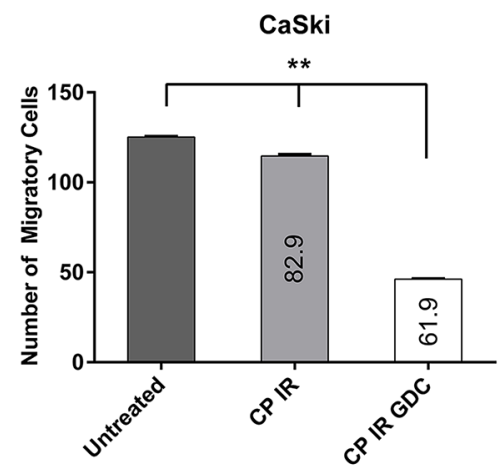

Figure 7: Cervical cancer cells expressing PIK3CA-E545K have a more migratory phenotype in transwell migration assays. A. The migratory properties of cervical cancer cell lines HeLa (PIK3CA-WT), HeLa cells overexpressing PIK3CA-E545K (HeLa-E545K) and CaSki (PIK3CA-WT plus PIK3CA-E545K) were analyzed by a migration assay using a Transwell Boyden chamber system. Cells were either untreated or pre-treated with $1 \mu \mathrm{M}$ GDC-0941 (formulated in DMSO) or an equivalent volume of DMSO (final concentration $0.01 \%$ ), radiation (2Gy) and cisplatin (formulated in PBS) at $1 \mu \mathrm{M}$ for 24 hours. Next day cells were seeded in the top chamber of the transwell migration apparatus. Media supplemented with $10 \%$ FBS was used as a chemoattractant in the lower chamber. Cells were incubated for $24 \mathrm{hr}$ at $37^{\circ} \mathrm{C}$ then non-migrated cells were removed from the upper face of the transwell insert using a cotton swab. Cells that migrated through membranes were stained with $1 \%$ crystal violet, $95 \%$ ethanol and then counted. Data are presented as means \pm S.E.M. from three different experiments. Scale bar $=100 \mu \mathrm{m}$. B. Quantitation of results from transwell migration assays in HeLa $(P I K 3 C A-$ $W T$ ). Different treatment conditions were compared using ordinary one-way ANOVA and Tukey's multiple comparisons test. $p$ values were $<0.0001$ for untreated vs cisplatin + IR group; untreated vs cisplatin + IR + GDC-0941; and cisplatin + IR + GDC-0941, indicated by ** The percent of migratory cells as a \% of untreated cells is shown on the graph. C. Quantitation of results from transwell migration assays in HeLa cells overexpressing PIK3CA-E545K (HeLa-E545K). Statistical comparisons were as in panel A. D. Quantitation of results from transwell migration assays in CaSki (PIK3CA-WT plus PIK3CA-E545K) cells, as in panels A and B. 
surveillance, tissue homoeostasis and wound healing [40], with PI3K signaling known to play a role in cellular migration [41]. Our results suggest that the PIK3CAE545K mutation is associated with an enhanced migratory phenotype in cervical cancer cells. These results are consistent with earlier studies in which normal human urothelial cells expressing PIK3CA-E545K were shown to have accelerated migration, compared to cells with wild type $P I K 3 C A$ [42]. Moreover, in the breast cancer cell line MDA-MB-231 modified to express either PIK3CA-E545K or H1047R, both displayed increased motility, with cells expressing $P I K 3 C A$-E545K showing increased directional migration [43]. Furthermore, functional analyses have shown that Akt can regulate migration and invasive processes [44-46].

The frequent activation of the PI3K pathway in many human cancers has led to intensive efforts to identify therapeutic agents that abrogate PI3K signaling and hence these agents may have clinical utility in patients with cancers that have an activated PI3K pathway. Numerous potent and selective PI3K inhibitors have recently entered early-phase clinical trials. Among them is GDC-0941, a PI3K pathway-inhibiting drug that is in advanced stages of clinical development. GDC-0941 is an oral class I pan$\mathrm{PI} 3 \mathrm{~K}$ inhibitor with activity in the nanomolar range against a wide range of cancer cell lines that has preclinical activity in models harbouring pathway alterations in PIK3CA, PTEN, or HER2 [24]. Currently GDC-0941 is in a phase II clinical trial in breast cancer patients [47]. Our studies showed that both enhanced migration and cisplatin resistance were abrogated by incubation of cervical cancer cell lines with GDC-0941. We also found that levels of Akt-pS473 were decreased by GDC-0941 treatment in a dose-dependent manner. Similarly, GDC-0941 has been shown to reduce RSK p380 phosphorylation in breast cancer cells expressing p110 $\beta$ activating mutations [48]. Our results also show that GDC-0941 was more toxic in cells expressing $P I K 3 C A$-E545K than cells expressing $P I K 3 C A-W T$, perhaps reflecting oncogene addiction in E545K expressing cells. Many PI3K pathway inhibitors as well as selective inhibitors of other components of the PI3K/AKT pathway are currently available, many in clinical trials [49]. It will be interesting to determine the effects of other PI3K/AKT/mTOR pathway inhibitors on cisplatin resistance, migration and overall survival in cells expressing PIK3CA-E545K, to determine whether these phenotypes are an inherent property of the cell signaling pathways in these cells or an effect exclusive to GDC0941. Such experiments may also shed light on pathways of PI3K-mediated cisplatin resistance and enhanced migration in cervical cancer cells expressing the $P I K 3 C A$ E545K mutation.

In summary, our studies suggest that targeting the PI3K pathway may represent a novel and promising strategy that may provide therapeutic benefit in cervical cancer patients whose tumours express PIK3CA-E545K, by restoring cisplatin sensitivity and possibly reducing a more migratory potential. However, it is important to note that to date, experiments have been carried out only on established transformed cells growing in culture. To further test this hypothesis, it will be important to validate our findings in freshly acquired patient cells as well as animal models of cervical cancer.

\section{MATERIALS AND METHODS}

\section{Cell culture}

A panel of cervical cancer cell lines including $\mathrm{SiHa}$ and CaSki was purchased from ATCC (Supplementary Table S1). SiHa (PIK3CA-wt) and CaSki (PIK3CA-wt/ $P I K 3 C A-E 545 \mathrm{~K})$ cell lines were cultured in MEM and RPMI (Invitrogen), respectively, supplemented with 10\% (v/v) fetal bovine serum (FBS, Hyclone III, Invitrogen) and penicillin (50 units/ml) and streptomycin $(50 \mu \mathrm{g} / \mathrm{ml})$. HeLa cells (PIK3CA-WT) were cultured in DMEM with $5 \%(\mathrm{v} / \mathrm{v})$ serum and antibiotics as above. Stable cell lines derived from parental HeLa cell line (described below and in Supplementary Material) were cultured in DMEM supplemented with 5\% fetal bovine serum, streptomycin and penicillin as above and other antibiotics as indicated below. All cell lines were cultured in a humidified incubator under an atmosphere of $5 \% \mathrm{CO}_{2}$ at $37^{\circ} \mathrm{C}$. SiHa, CaSki and HeLa cell lines were authenticated by STR analysis by ATCC January 2016.

\section{Confirmation of PIK3CA status in cell lines}

Total DNA was extracted from cell lines using a DNeasy Blood and Tissue Kit (QIAGEN, catalogue No. 69506) and PIK3CA status was confirmed as described previously [27] (Supplementary Table S1).

\section{Transfection and generation of stable cell lines}

To deplete PIK3CA, HeLa cells were transfected with pRS retroviral vector encoding one of four unique shRNA sequences to PIK3CA (OriGene catalogue number: TR310428). Twenty-four hours after transfection, cells were placed in DMEM containing 5\% fetal bovine serum and $2.5 \mu \mathrm{g} / \mathrm{ml}$ puromycin (Sigma- Aldrich, MO, USA) and after two weeks, single cell populations were isolated and evaluated for PI3K protein expression by western blot. Based on low expression of $\mathrm{p} 110 \alpha$ protein, a cell line expressing shRNA plasmid A, that we named A5, was selected for further study (Supplementary Figure S1).

For re-expression of shRNA-resistant PIK3CA$W T$ and $P I K 3 C A$-E545K, three mutations at the shRNA target site (Q981, C984, Y985) were generated in PIK3CA cDNA (bearing a C-terminal Myc and DDK tag) in the pCMV6 Entry vector (OriGene, Catalogue number RC213112) using a Quikchange Site Directed Mutagenesis 
kit (Stratagene). Mutation of E545K was carried out in a similar manner. A5 cells were then transfected with vectors for shRNA-resistant PIK3CA-WT, shRNAresistant $P I K 3 C A$-E545K or empty vector as a control using Lipofectamine 2000 according to the manufacturers recommended conditions. The transfected cells were selected by growth in medium containing $2.5 \mu \mathrm{g} / \mathrm{ml}$ puromycin and $600 \mu \mathrm{g} / \mathrm{ml} \mathrm{G418} \mathrm{(Sigma-} \mathrm{Aldrich,} \mathrm{MO,}$ USA). HeLa cells over-expressing PIK3CA-E545K (to create cells expressing both endogenous $P I K 3 C A-\mathrm{WT}$ and Myc, DDK-tagged $P I K 3 C A$-E545K) were generated in a similar manner except that selection was carried out using $400 \mu \mathrm{g} / \mathrm{ml} \mathrm{G} 418$. After 14 days, single cell populations were isolated and characterized for relative expression of p110/PIK3CA by western blot. Cell lines A5-WT4, A5E545K5 and HeLa-E545K (Supplementary Figure S1) were selected for further study. Mutations introduced into vectors were confirmed by sequencing at the University of Calgary DNA sequencing Centre. Primer sequences and detailed procedures are available upon request.

\section{Cell treatments}

The PI3K/Akt inhibitor GDC-0941 was purchased from Selleck Chemicals, dissolved in $1 \mathrm{ml}$ DMSO to a concentration of $10 \mathrm{mM}$ and stored at $-80^{\circ} \mathrm{C}$. Cisplatin was purchased from Sigma, suspended in PBS (containing 154 $\mathrm{mM} \mathrm{NaCl}$ ) as described [29] and stored at $-20^{\circ} \mathrm{C}$. Where indicated, GDC-0941, cisplatin or appropriate controls, as described above, were added directly to the cell media at the concentrations indicated. Irradiation was carried out using a GammaCell1000 Elite ${ }^{137} \mathrm{Cs}$ source (MDS Nordion) with a dose rate of approximately $2.9 \mathrm{~Gy} / \mathrm{min}$, as described previously [50].

\section{Immunoblots}

Cells were lysed in an ice cold NETN lysis buffer [150 mM NaCl, 0.2 mM EDTA, 50 mM Tris-HCl (pH 7.5), and $1 \%(\mathrm{v} / \mathrm{v}) \mathrm{NP}-40]$ containing protein phosphatase and protease inhibitors $(1 \mu \mathrm{M}$ microcystin-LR, $0.2 \mathrm{mM}$ phenylmethylsulfonyl fluoride, $0.1 \mu \mathrm{g} / \mathrm{mL}$ pepstatin, $0.1 \mu \mathrm{g} / \mathrm{mL}$ aprotinin, and $0.1 \mu \mathrm{g} / \mathrm{mL}$ leupeptin), and lysed on ice by sonication ( 2 x $5 \mathrm{~s}$ bursts using a Fisher Scientific Sonic Dis-membrator Model 100). Total protein [50 $\mu \mathrm{g}$; as determined by the Detergent-Compatible Protein Assay (Bio- Rad, CA, USA) using bovine serum albumin as standard] was resolved by SDS-PAGE and electrophoretically transferred onto nitrocellulose membranes. Membranes were blocked with 20\% (w/v) skim milk powder in T-TBS buffer $[20 \mathrm{mM}$ Tris- $\mathrm{HCl}$ (pH 7.5), $500 \mathrm{mM} \mathrm{NaCl}$, and 0.1\% (v/v) Tween 20] for 1 hour and probed with antibodies to total proteins or phosphorylated proteins as indicated. Antibodies to p110 beta, Myc, PTEN, total RSK, RSK pSer 380 and total Akt were purchased from Cell Signaling. Antibodies to p85 and Ku80 were from Abcam, and the antibody to Akt
pSer473 was from Santa Cruz. The antibody to p110 $\alpha$ was kindly provided by Prof. Bart Vanhaesebroeck and Dr. Mariona Graupera (Centre for Cell Signaling, University of London, UK). Western blots were washed in TTBS and after incubation with the appropriate secondary antibody, and developed using ECL reagent (Perkin Elmer) and Fuji X-Ray film. All experiments were repeated at least 3 times. For quantitation, immunoblots were scanned at 300 dpi grayscale, quantitated using Image J software and normalized to Ku80 (loading control). The mean of three experiments with SEM is shown.

\section{Clonogenic survival assays}

Cells were trypsinized, seeded in $4 \mathrm{~mL}$ medium and incubated overnight before irradiation or treatment with cisplatin or GDC-0941, as described below. After 14 days, cells were fixed then stained with crystal violet as described previously [50] and colonies (greater than 50 cells) were counted. Survival curves were plotted using Prism 6.0 Software (GraphPad). Where indicated, cells were irradiated with 1,2 , 4, or 6 Gy IR or incubated with increasing doses of cisplatin $(0.1,0.5,1$ or $2 \mu \mathrm{M})$ made up in PBS or an equal volume of PBS as vehicle control. GDC-0941 or an equal volume of DMSO (to give a final concentration of $0.01 \%$ ) was added at 0.01 , 0.1 and $0.5 \mu \mathrm{M}$. Unless otherwise indicated, cisplatin was removed after 24 hours. Each experiment was carried out in triplicate and results from three separate experiments are shown.

\section{Serum starvation}

Stable cells expressing the PIK3CA-E545K mutation and/or wild-type $P I K 3 C A$ were plated on $10 \mathrm{~cm}$ dishes in DMEM supplemented with $5 \%(\mathrm{v} / \mathrm{v})$ fetal bovine serum and incubated for 24 hours. The media was then replaced with DMEM supplemented with $2 \%(\mathrm{v} / \mathrm{v})$ serum for 48 hours. The concentration of serum in the media was then reduced to $0.2 \%(\mathrm{v} / \mathrm{v})$ and cells were harvested and cell lysates were prepared after an additional 48 hours incubation.

\section{Wound healing assay}

Cells were plated in $6 \mathrm{~cm}$ tissue culture dishes and grown to confluency. After $24 \mathrm{hrs}$ cells were either left untreated or treated with $1 \mu \mathrm{M}$ GDC-0941 (formulated in DMSO) or an equivalent volume of DMSO (final concentration $0.01 \%$ ) as control, treated with radiation (2 Gy) and cisplatin (formulated in PBS) at $1 \mu \mathrm{M}$ or treated with $1 \mu \mathrm{M}$ GDC-0941 (formulated in DMSO) radiation (2 Gy) and cisplatin (formulated in PBS) at $1 \mu \mathrm{M}$. 24hrs after treatment, scratches were made with a sterile $200 \mu \mathrm{L}$ pipette tip and wound healing was observed $0,6,24$, and 48 hours after initiation of the scratch. At different time points, images were generated using a Carl Zeiss Axiovert 
200M microscope at $10 \mathrm{x}$ magnification and imported into Photoshop Creative Suite, version 6.0. The rate of migration was measured by quantifying the total distance between the edges of the scratch as described previously [51]. Each experiment was repeated at least 3 times.

\section{Transwell migration assays}

Transwell migration experiment was performed in HeLa, CaSki and HeLa-E545K cells using 24-well Transwell Boyden chamber system $(8 \mu \mathrm{m}$-pore size, Corning, New York, USA). Cells were either left untreated or treated with $1 \mu \mathrm{M}$ GDC-0941 (formulated in DMSO), or an equivalent volume of DMSO (final concentration $0.01 \%$ ) as control, treated with radiation (2 Gy) and cisplatin (formulated in PBS) at $1 \mu \mathrm{M}$ or treated with $1 \mu \mathrm{M}$ GDC0941 (formulated in DMSO) radiation (2 Gy) and cisplatin (formulated in PBS) at $1 \mu \mathrm{M}$. Cells were seeded in the top chamber to perform transwell migration assay. Media supplemented with $10 \%$ FBS was used as a chemoattractant in the lower chamber. The cells were incubated for $24 \mathrm{hr}$ at $37^{\circ} \mathrm{C}$. Non-migrated cells were removed from the upper face of the transwell insert using a cotton swab. Cells that migrated through membranes were stained with $1 \%$ crystal violet, $95 \%$ ethanol and then counted. The results are representative of three independent experiments.

\section{Statistical analysis}

Results are expressed as means \pm SEM. For Figures 1-6, statistical significance was determined using multiple t-tests with the Holm-Sidak method to correct for multiple comparisons. For Figure 7, ordinary oneway ANOVA with no matching or pairing and Tukey's multiple comparisons test was used. Statistical analysis was performed using GraphPad Prism 6.0 Software. $p$ values of $<0.05$ were considered statistically significant.

\section{ACKNOWLEDGEMENTS}

We thank Prof. Bart Vanhaesebroeck and Dr. Mariona Graupera, University of London for the p110 alpha antibody and Drs. S. Grewal and J. Chan for use of their microscope.

\section{CONFLICTS OF INTEREST}

The authors declare they have no conflict of interest.

\section{GRANT SUPPORT}

This work was supported by grant \#201201293 from Alberta Innovates Health Solutions (CMD and SPLM) and the Engineered Air Chair in Cancer Research (SPLM). WA was supported by a post-doctoral fellowship from the Alberta Cancer Foundation.

\section{REFERENCES}

1. Bosch A, Li Z, Bergamaschi A, Ellis H, Toska E, Prat A, Tao JJ, Spratt DE, Viola-Villegas NT and Castel P. PI3K inhibition results in enhanced estrogen receptor function and dependence in hormone receptor-positive breast cancer. Science Translational Medicine. 2015; 7:283ra251-283ra251.

2. Noguchi S, Yasui Y, Iwasaki J, Kumazaki M, Yamada N, Naito S and Akao Y. Replacement treatment with microRNA-143 and-145 induces synergistic inhibition of the growth of human bladder cancer cells by regulating PI3K/Akt and MAPK signaling pathways. Cancer Letters. 2013; 328:353-361.

3. Wang LC, Kim SS, Nanus DM and Cantley LC. Abstract A33: Utilizing insulin the treatment of prostate cancer with BKM120 abrogates the therapeutic effect of PI3K pathway inhibition. Molecular Cancer Therapeutics. 2015; 14:A33-A33.

4. Byeon HK, Na HJ, Yang YJ, Kwon HJ, Chang JW, Ban MJ, Kim WS, Shin DY, Lee EJ and Koh YW. c-Metmediated reactivation of PI3K/AKT signaling contributes to insensitivity of BRAF (V600E) mutant thyroid cancer to BRAF inhibition. Molecular Carcinogenesis. 2015. doi: 10.1002/mc.22418. [Epub ahead of print]

5. Mabuchi S, Kuroda H, Takahashi $\mathrm{R}$ and Sasano T. The $\mathrm{PI} 3 \mathrm{~K} / \mathrm{AKT} / \mathrm{mTOR}$ pathway as a therapeutic target in ovarian cancer. Gynecologic Oncology. 2015; 137:173-179.

6. Yao W, Yue P, Zhang G, Owonikoko TK, Khuri FR and Sun S-Y. Enhancing therapeutic efficacy of the MEK inhibitor, MEK162, by blocking autophagy or inhibiting $\mathrm{PI} 3 \mathrm{~K} /$ Akt signaling in human lung cancer cells. Cancer Letters. 2015; 364:70-78.

7. Karakas B, Bachman K and Park B. Mutation of the PIK3CA oncogene in human cancers. British Journal of Cancer. 2006; 94:455-459.

8. Kong D and Yamori T. Phosphatidylinositol 3-kinase inhibitors: promising drug candidates for cancer therapy. Cancer Science. 2008; 99:1734-1740.

9. Akinleye A, Avvaru P, Furqan M, Song Y and Liu D. Phosphatidylinositol 3-kinase (PI3K) inhibitors as cancer therapeutics. J Hematol Oncol. 2013; 6:88.

10. Hafsi S, Pezzino FM, Candido S, Ligresti G, Spandidos DA, Soua Z, McCubrey JA, Travali S and Libra M. Gene alterations in the PI3K/PTEN/AKT pathway as a mechanism of drug-resistance (review). International Journal of Oncology. 2012; 40:639-644.

11. Corvera S and Czech MP. Direct targets of phosphoinositide 3-kinase products in membrane traffic and signal transduction. Trends in Cell Biology. 1998; 8:442-446.

12. Clark AS, West K, Streicher S and Dennis PA. Constitutive and inducible Akt activity promotes resistance to chemotherapy, trastuzumab, or tamoxifen in breast cancer cells. Molecular Cancer Therapeutics. 2002; 1:707-717. 
13. Kang S, Bader AG and Vogt PK. Phosphatidylinositol 3-kinase mutations identified in human cancer are oncogenic. Proceedings of the National Academy of Sciences of the United States of America. 2005; 102:802-807.

14. Samuels Y, Diaz LA, Schmidt-Kittler O, Cummins JM, DeLong L, Cheong I, Rago C, Huso DL, Lengauer C and Kinzler KW. Mutant PIK3CA promotes cell growth and invasion of human cancer cells. Cancer Cell. 2005; 7:561-573.

15. Laplante $M$ and Sabatini DM. mTOR signaling in growth control and disease. Cell. 2012; 149:274-293.

16. Engelman JA, Luo J and Cantley LC. The evolution of phosphatidylinositol 3-kinases as regulators of growth and metabolism. Nature Reviews Genetics. 2006; 7:606-619.

17. Ihle NT, Lemos R, Wipf P, Yacoub A, Mitchell C, Siwak D, Mills GB, Dent P, Kirkpatrick DL and Powis G. Mutations in the phosphatidylinositol-3-kinase pathway predict for antitumor activity of the inhibitor PX-866 whereas oncogenic Ras is a dominant predictor for resistance. Cancer Research. 2009; 69:143-150.

18. Kong $\mathrm{D}$, Yamori $\mathrm{T}$, Yamazaki $\mathrm{K}$ and Dan $\mathrm{S}$. In vitro multifaceted activities of a specific group of novel phosphatidylinositol 3-kinase inhibitors on hotspot mutant PIK3CA. Investigational New Drugs. 2014; 32:1134-1143.

19. O'Brien C, Wallin JJ, Sampath D, GuhaThakurta D, Savage H, Punnoose EA, Guan J, Berry L, Prior WW and Amler LC. Predictive biomarkers of sensitivity to the phosphatidylinositol 3' kinase inhibitor GDC-0941 in breast cancer preclinical models. Clinical Cancer Research. 2010; 16:3670-3683.

20. Isakoff SJ, Engelman JA, Irie HY, Luo J, Brachmann SM, Pearline RV, Cantley LC and Brugge JS. Breast cancerassociated PIK3CA mutations are oncogenic in mammary epithelial cells. Cancer Research. 2005; 65:10992-11000.

21. Black JD, Lopez S, Cocco E, Bellone S, Altwerger G, Schwab CL, English DP, Bonazzoli E, Predolini F, Ferrari F, Ratner E, Silasi DA, Azodi M, Schwartz PE and Santin AD. PIK3CA oncogenic mutations represent a major mechanism of resistance to trastuzumab in HER2/neu overexpressing uterine serous carcinomas. British J. Cancer. 2015; 113:1020-1026.

22. Lackner MR. Prospects for personalized medicine with inhibitors targeting the RAS and PI3K pathways. Expert Rev Mol Diagn. 2010;10:75-87.

23. Folkes AJ, Ahmadi K, Alderton WK, Alix S, Baker SJ, Box G, Chuckowree IS, Clarke PA, Depledge P and Eccles SA. The identification of 2-(1 H-Indazol-4-yl)-6(4-methanesulfonyl-piperazin-1-ylmethyl)-4-morpholin4-yl-thieno [3, 2-d] pyrimidine (GDC-0941) as a potent, selective, orally bioavailable inhibitor of class I PI3 kinase for the treatment of cancer $\dagger$. Journal of Medicinal Chemistry. 2008; 51:5522-5532.

24. Raynaud FI, Eccles SA, Patel S, Alix S, Box G, Chuckowree I, Folkes A, Gowan S, Brandon ADH and Di
Stefano F. Biological properties of potent inhibitors of class I phosphatidylinositide 3-kinases: from PI-103 through PI-540, PI-620 to the oral agent GDC-0941. Molecular cancer therapeutics. 2009; 8:1725-1738.

25. Arteaga CL. (2010). Clinical development of phosphatidylinositol-3 kinase pathway inhibitors. Phosphoinositide 3-kinase in Health and Disease: Springer), pp. 189-208.

26. Martini M, Ciraolo E, Gulluni F and Hirsch E. Targeting PI3K in cancer: any good news? Frontiers in oncology. 2013; 3: 108.

27. McIntyre JB, Wu JS, Craighead PS, Phan T, Köbel M, Lees-Miller SP, Ghatage P, Magliocco AM and Doll CM. PIK3CA mutational status and overall survival in patients with cervical cancer treated with radical chemoradiotherapy. Gynecologic Oncology. 2013; 128:409-414.

28. Lou H, Villagran G, Boland JF, Im KM, Polo S, Zhou W, Odey U, Juárez-Torres E, Medina-Martínez I and RomanBasaure E. Genome Analysis of Latin American Cervical Cancer: Frequent Activation of the PIK3CA Pathway. Clinical Cancer Research. 2015; 21:5360-5370.

29. Hall MD, Telma KA, Chang K-E, Lee TD, Madigan JP, Lloyd JR, Goldlust IS, Hoeschele JD and Gottesman MM. Say No to DMSO: dimethylsulfoxide inactivates cisplatin, carboplatin, and other platinum complexes. Cancer Research. 2014; 74:3913-3922.

30. Engelman JA, Mukohara T, Zejnullahu K, Lifshits E, Borrás AM, Gale C-M, Naumov GN, Yeap BY, Jarrell $\mathrm{E}$ and Sun J. Allelic dilution obscures detection of a biologically significant resistance mutation in EGFRamplified lung cancer. Journal of Clinical Investigation. 2006; 116:2695.

31. Isakoff SJ, Engelman JA, Irie HY, Luo J, Brachmann SM, Pearline RV, Cantley LC and Brugge JS. Breast cancerassociated PIK3CA mutations are oncogenic in mammary epithelial cells. Cancer Research. 2005; 65:10992-11000.

32. Romeo Y, Moreau J, Zindy PJ, Saba-El-Leil M, Lavoie G, Dandachi F, Baptissart M, Borden KL, Meloche S and Roux PP. RSK regulates activated BRAF signaling to $\mathrm{mTORC} 1$ and promotes melanoma growth. Oncogene. 2013; 32:2917-2926.

33. Wallin JJ, Guan J, Prior WW, Lee LB, Berry L, Belmont LD, Koeppen H, Belvin M, Friedman LS and Sampath D. GDC-0941, a novel class I selective PI3K inhibitor, enhances the efficacy of docetaxel in human breast cancer models by increasing cell death in vitro and in vivo. Clinical Cancer Research. 2012; 18:3901-3911.

34. Torre LA, Bray F, Siegel RL, Ferlay J, Lortet-Tieulent J and Jemal A. Global cancer statistics, 2012. CA Cancer J Clin. 2015; 65:87-108.

35. Reducing uncertainties about the effects of chemoradiotherapy for cervical cancer: individual patient data meta-analysis. The Cochrane Database of Systematic Reviews. 2010; Cd008285. 
36. Petrelli F, De Stefani A, Raspagliesi F, Lorusso D and Barni S. Radiotherapy with concurrent cisplatin-based doublet or weekly cisplatin for cervical cancer: a systematic review and meta-analysis. Gynecologic Oncology. 2014; 134:166-171.

37. Brown KK and Toker A. The phosphoinositide 3-kinase pathway and therapy resistance in cancer. F1000prime Reports. 2015; 7:13.

38. Amable L. Cisplatin resistance and opportunities for precision medicine. Pharmacol Res. 2016; 106:27-36.

39. Lopez-Martinez D, Liang CC and Cohn MA. Cellular response to DNA interstrand crosslinks: the Fanconi anemia pathway. Cellular and molecular life sciences. 2016 Apr 19.

40. Sivamani K, Garcia MS and Isseroff RR. Wound re-epithelialization: modulating keratinocyte migration in wound healing. Frontiers in Bioscience. 2006; 12:2849-2868.

41. Cain RJ and Ridley AJ. Phosphoinositide 3-kinases in cell migration. Biology of the Cell. 2009; 101:13-29.

42. Ross R, Askham J and Knowles M. PIK3CA mutation spectrum in urothelial carcinoma reflects cell contextdependent signaling and phenotypic outputs. Oncogene. 2013; 32:768-776.

43. Pang H, Flinn R, Patsialou A, Wyckoff J, Roussos ET, Wu H, Pozzuto M, Goswami S, Condeelis JS and Bresnick AR. Differential enhancement of breast cancer cell motility and metastasis by helical and kinase domain mutations of class IA phosphoinositide 3-kinase. Cancer Research. 2009; 69:8868-8876.

44. Kim D, Kim S, Koh H, Yoon SO, Chung AS, Cho KS and Chung J. Akt/PKB promotes cancer cell invasion via increased motility and metalloproteinase production. FASEB journal : official publication of the Federation of American Societies for Experimental Biology. 2001; 15:1953-1962.
45. Suzuki A, Lu J, Kusakai G, Kishimoto A, Ogura T and Esumi H. ARK5 is a tumor invasion-associated factor downstream of Akt signaling. Mol Cell Biol. 2004; 24:3526-3535.

46. Vasko V, Saji M, Hardy E, Kruhlak M, Larin A, Savchenko V, Miyakawa M, Isozaki O, Murakami H, Tsushima T, Burman KD, De Micco C and Ringel MD. Akt activation and localisation correlate with tumour invasion and oncogene expression in thyroid cancer. Journal of Medical Genetics. 2004; 41:161-170.

47. Krop I, Johnston S, Mayer IA, Dickler M, Ganju V, ForeroTorres A, Melichar B, Morales S, de Boer R and Gendreau S. Abstract S2-02: The FERGI phase II study of the PI3K inhibitor pictilisib (GDC-0941) plus fulvestrant vs fulvestrant plus placebo in patients with ER+, aromatase inhibitor (AI)resistant advanced or metastatic breast cancer-Part I results. Cancer Research. 2015; 75:S2-02-S02-02.

48. Nakanishi Y, Walter K, Spoerke JM, O’Brien C, Huw LY, Hampton GM and Lackner MR. Activating Mutations in PIK3CB Confer Resistance to PI3K Inhibition and Define a Novel Oncogenic Role for p110beta. Cancer Res. 2016; 76:1193-203.

49. Moschetta M, Reale A, Marasco C, Vacca A and Carratu MR. Therapeutic targeting of the mTOR-signaling pathway in cancer: benefits and limitations. British Journal of Pharmacology. 2014; 171:3801-3813.

50. Douglas P, Zhong J, Ye R, Moorhead GB, Xu X and Lees-Miller SP. Protein phosphatase 6 interacts with the DNA-dependent protein kinase catalytic subunit and dephosphorylates $\gamma$-H2AX. Molecular and Cellular Biology. 2010; 30:1368-1381.

51. Liang CC, Park AY and Guan JL. In vitro scratch assay: a convenient and inexpensive method for analysis of cell migration in vitro. Nat. Protoc. 2007; 2:329-333. 